\title{
Adenosine to Guanosine Transition Abnormality
}

National Cancer Institute

\section{Source}

National Cancer Institute. Adenosine to Guanosine Transition Abnormality. NCI

Thesaurus. Code C45640.

A point mutation involving the substitution of Guanosine (a purine base) for Adenosine (a purine base) in a DNA sequence from eukaryotic or prokaryotic organisms. This abnormality can be either heritable or occur somatically. 